\section{Effects of Long-Term Ingestion of Cadmium- Polluted Rice or Low-Dose Cadmium-Supplemented Diet on the Endogenous Copper and Zinc Balance in Female Rats}

\author{
Junichi Nakagawa, ${ }^{*, a}$ Shinshi Oishi, ${ }^{a}$ \\ Jin Suzuki, ${ }^{b}$ Yoshiteru Tsuchiya, ${ }^{c}$ \\ Masanori Ando, ${ }^{d}$ and Yasuo Fujimoto ${ }^{e}$
}

${ }^{a}$ Department of Environmental Health and Toxicology, ${ }^{b}$ Department of Food Safety, Tokyo Metropolitan Institute of Public Health, 3-24-1, Hyakunincho, Shinjuku-ku, Tokyo 1690073, Japan, ${ }^{c}$ Cooperative Research and Development Center Yokohama National University, 79-5 Tokiwadai, Hodogaya-ku, Yokohama, Kanagawa 240-8501, Japan, 'Division of Environmental Chemistry, National Institute of Health Science, 1-181 Kamiyoga, Setagaya-ku, Tokyo 158-8501, Japan, and ${ }^{e}$ College of Pharmacy, Nihon University, 7-7-1 Narashinodai, Funabashi, Chiba 274-8555, Japan

(Received October 2, 2003; Accepted October 8, 2003)

The concentrations of endogenous copper $(\mathrm{Cu})$ and zinc $(\mathrm{Zn})$ in the liver and kidney of female rats were measured after ingestion of cadmium $(\mathrm{Cd})$-polluted (1.06 ppm) rice or cadmium-supplemented (1.1, 5,20 , and $40 \mathrm{ppm}$ ) rice for 12,18 , and 22 months. In the liver, the $\mathrm{Cd}$ concentration increases in a dose-dependent manner for the first 18 months. After 18 months, the concentration remained stationary in the low-dose groups, increased in the 5-ppm group, and decreased in the 20- and 40-ppm groups. The $\mathrm{Cu}$ concentration was almost unchanged through the experiment, and the $\mathrm{Zn}$ concentration increased in a dose-dependent manner. In the kidneys, changes in the $\mathrm{Cd}$ concentration resembled that in the liver. The concentrations of $\mathrm{Cu}$ increased in a dose-dependent manner at 12 and 18 months. The $Z n$ concentration increased more in the 5-ppm group but not dose dependently.

Key words — cadmium, zinc, copper, cadmium-polluted rice, rats

\footnotetext{
*To whom correspondence should be addressed: Department of Environmental Health and Toxicology, Tokyo Metropolitan Institute of Public Health, 3-24-1, Hyakunincho, Shinjuku-ku, Tokyo 169-0073, Japan. Tel.: +81-3-3363-3231; Fax: +81-33368-4060; E-mail: junichi_2_nakagawa@member.metro.tokyo. jp
}

\section{INTRODUCTION}

Cadmium $(\mathrm{Cd})$ is a metallic element widely recognized as being toxic to humans and animals which can reach humans through contaminated foodstuffs. ${ }^{1-3)}$ Epidemiologic surveys have shown that the average Cd intake ranges from 13 to $20 \mu \mathrm{g} /$ day in the USA and European Union, ${ }^{4-7)}$ and from 27 to $100 \mu \mathrm{g} /$ day in Japan. ${ }^{89}{ }^{89}$ In countries where rice is consumed in large quantities, rice becomes a major source of Cd intake. According to the Food Sanitation Law of Japan, the concentration of $\mathrm{Cd}$ in rice must not exceed $1 \mathrm{ppm}$, and if the concentration exceeds $0.4 \mathrm{ppm}$ the rice is considered "semipolluted" and must not be used for human consumption. Several recent surveys have reported that Japanese rice has the highest $\mathrm{Cd}$ concentrations of all Asian countries studied, ${ }^{9,10)}$ and consequently the daily intake from rice is estimated to be as high as Cd 5.2-29.8 $\mu$ g per adult. ${ }^{9)}$

The results of acute and chronic Cd intoxication of laboratory animals include various degrees of liver and kidney damage. $\mathrm{Cd}$ also alters the distribution of several essential elements ${ }^{11-13)}$ that play very important roles in biological systems ${ }^{14)}$ Cadmium accumulation may therefore cause significant changes in the homeostasis of the essential elements, which, in turn, results in several diseases related to either deficiencies or excesses of such elements.

Recently, we have investigated the intestinal absorption of $\mathrm{Cd}$ and hepatorenal toxicity in female rats given low amounts of Cd-polluted rice. ${ }^{15,16)}$ The results showed that the retention rate of $\mathrm{Cd}$ did not change with the dosage or the treatment period and that renal toxicity was not induced by long-term oral administration of low amounts of $\mathrm{Cd}$, in contrast to the effects of high-dose $\mathrm{Cd}$ administration, although tissue accumulation occurs.

In the present study, the concentration of important endogenous metals, copper $(\mathrm{Cu})$ and zinc $(\mathrm{Zn})$, in the liver and kidneys of rats chronically fed Cdpolluted rice or a low-level Cd-supplemented diet were investigated to establish the effects on these metal balances as a counterpart to the previous absorption and toxicity studies.

\section{MATERIALS AND METHODS}

Experimental Design — A total of 300 female Sprague-Dawley rats, aged 5 weeks, were obtained from Charles-River Japan (Yokohama, Japan). 
Table 1. Cadmium Concentration in Diets and their Compositions

\begin{tabular}{|c|c|c|c|c|c|}
\hline Group & $\begin{array}{l}\text { Cd concentration in the diets } \\
(\mathrm{ppm})\end{array}$ & $\begin{array}{c}\text { Purified diet } \\
(\%) \\
\end{array}$ & $\begin{array}{c}\text { Ordinary rice } \\
(\%) \\
\end{array}$ & $\begin{array}{c}\text { Cd-polluted rice } \\
(\%)^{a)} \\
\end{array}$ & $\begin{array}{c}\mathrm{CdCl}_{2} \text { Supplement } \\
(\mathrm{ppm})^{b)}\end{array}$ \\
\hline $\bar{I}$ & 0.02 & 28.0 & 72.0 & - & - \\
\hline II & 1.06 & 28.0 & - & 72.0 & - \\
\hline III & 1.12 & 28.0 & 72.0 & - & 1.1 \\
\hline IV & 4.86 & 28.0 & 72.0 & - & 5 \\
\hline V & 20.1 & 28.0 & 72.0 & - & 20 \\
\hline VI & 39.5 & 28.0 & 72.0 & - & 40 \\
\hline
\end{tabular}

a) Cadmium concentration in the polluted rice is approximately $1.5 \mathrm{ppm} . b) \mathrm{CdCl}_{2}$ supplemented the mixture of purified diet and ordinary rice to obtain the set concentrations of cadmium in the diets.

Six groups of rats, each consisting of 50 animals, were fed diets containing low amounts of Cd chloride or Cd-polluted rice (Table 1). Rats were given diets consisting of $28 \%$ purified and $72 \%$ ordinary rice (unpolluted or Cd-polluted rice prepared by Oriental Yeast Co. Ltd., Tokyo, Japan). Group I was fed a mixture of purified and ordinary rice and was used as a negative control. Group II was fed a diet of purified rice mixed with $\mathrm{Cd}$-polluted rice with a $\mathrm{Cd}$ content of $1.1 \mathrm{ppm}$ to examine the toxic effects of $\mathrm{Cd}$ from rice origin. Groups III-VI were fed a mixture of purified and ordinary rice and $\mathrm{CdCl}_{2}$ with $\mathrm{Cd}$ contents of 1.1, 5, 20, and $40 \mathrm{ppm}$. After the commencement of the feeding experiment, the rats were examined daily for clinical signs and weighed once weekly.

The animals in each group were killed at 12,18 , and 22 months (10, 5-7, and all surviving animals, respectively). The rats were deprived of food for $16 \mathrm{hr}$ or more prior to death. The experiment was terminated at month 22 because the total number of surviving animals in the 20-ppm $\mathrm{CdCl}_{2}$-treated group reached the minimum necessary for subsequent analyses of chronic $\mathrm{Cd}$ toxicity.

\section{Determination of $\mathrm{Cd}, \mathrm{Cu}$, and $\mathrm{Zn}$ Levels}

Analytical Procedure: The samples $(0.1-10 \mathrm{~g})$ were weighed into a decomposition vessel, to which $3 \mathrm{ml}$ of $\mathrm{HNO}_{3}$ was added. Decomposition vessels were soaked in $10 \% \mathrm{HNO}_{3}$ solution for $48 \mathrm{hr}$ and rinsed with water before use. The sample was decomposed in a microwave oven decomposition system under increased pressure. After being cooled to room temperature, the contents of the vessel were placed in a test tube to which water was added to make $10 \mathrm{ml}$ of sample solution. The sample solution was diluted with water to which yttrium and indium solutions were added as internal standards. $\mathrm{Cd}, \mathrm{Cu}$, and $\mathrm{Zn}$ levels in the sample solution were determined with a indyctively coupled plasma-mass spectrometry (ICP-MS) (HP4500; Hewlett Packard Electric Co., Tokyo, Japan). Calibration curves for the determination of ${ }^{106} \mathrm{Cd}$, total $\mathrm{Cd}, \mathrm{Cu}$, and $\mathrm{Zn} \mathrm{lev-}$ els were prepared from the analytical values of the corresponding standard solutions containing internal standard substances. The internal standard method was applied to calculate those levels.

Statistical Analysis: Statistical analyses were performed to evaluate differences between control and Cd-polluted rice or $\mathrm{CdCl}_{2}$-treated animals using the following methods. ${ }^{17)}$ Data were analyzed for homogeneity of variance using Bartlett's test.

When the variance was homogeneous among groups, a one-way analysis of variance (ANOVA) was carried out. If significant differences were found using ANOVA, the mean value for each Cd-treated group was compared to that of the controls using Dunnett's test. When the variance was heterogeneous based on Bartlett's test, the Kruskal-Wallis' test was used to check for differences among groups. If significant differences were found, a Dunnet-type ranksum test was performed. Comparison of different effects was made using Pearson's correlation analysis. The level of significance was set at $p<0.05$.

\section{RESULTS}

\section{Concentration of $\mathrm{Cd}, \mathrm{Cu}$, and $\mathrm{Zn}$ in the Liver}

$\mathrm{Cd}, \mathrm{Cu}$, and $\mathrm{Zn}$ concentrations in the liver are shown in Table 2. When compared within the same treatment periods, the $\mathrm{Cd}$ concentration increased in a dose-dependent manner for the first 18 months of exposure. After 18 months, the concentration remained stationary in the low-dose groups, increased in the 5-ppm group, and decreased in the 20- and 40-ppm groups.

The $\mathrm{Cu}$ concentration remained almost unchanged throughout the experimental period (6 to 
Table 2. Concentrations of $\mathrm{Cd}, \mathrm{Cu}$, and $\mathrm{Zn}$ in the Liver of Rats Fed Cd-Polluted Rice or Cd-Supplemented Diet for 12, 18, and 22 months

\begin{tabular}{|c|c|c|c|}
\hline Group & 12 months & 18 months & 22 months \\
\hline \multicolumn{4}{|l|}{$\mathrm{Cd}$} \\
\hline I & nd & $0.058 \pm 0.035^{a)}$ & $\left.0.032 \pm 0.027^{a}\right)$ \\
\hline II & $0.20 \pm 0.12$ & $2.8 \pm 2.3^{a)}$ & $2.7 \pm 2.2^{a)}$ \\
\hline III & $1.0 \pm 1.4^{b)}$ & $2.0 \pm 2.1$ & $1.7 \pm 1.7$ \\
\hline IV & $2.0 \pm 1.7^{b)}$ & $\pm 12^{a, b)}$ & $\pm 18^{a, b)}$ \\
\hline V & $16 \pm 8^{b)}$ & $\pm 33^{a, b)}$ & $\pm 15^{a, b)}$ \\
\hline VI & $32 \pm 12^{b)}$ & $\pm 42^{a, b)}$ & $\pm 20^{a, b)}$ \\
\hline \multicolumn{4}{|l|}{$\mathrm{Cu}$} \\
\hline I & $8.6 \pm 2.4$ & \pm 21 & $8.6 \pm 2.7$ \\
\hline II & $8.0 \pm 1.8$ & \pm 4 & $9.7 \pm 4.1$ \\
\hline III & $12 \pm 8$ & $6.3 \pm 1.4$ & \pm 6 \\
\hline IV & $8.8 \pm 2.1$ & $8.6 \pm 4.0$ & $7.2 \pm 1.7$ \\
\hline V & $8.4 \pm 1.3$ & $9.1 \pm 3.3$ & $8.7 \pm 4.4$ \\
\hline VI & $9.1 \pm 1.7$ & $9.5 \pm 5.2$ & $7.4 \pm 1.5$ \\
\hline \multicolumn{4}{|l|}{$\mathrm{Zn}$} \\
\hline I & $37 \pm 3$ & \pm 5 & \pm 6 \\
\hline II & $39 \pm 4$ & \pm 5 & \pm 7 \\
\hline III & $42 \pm 7$ & \pm 7 & \pm 12 \\
\hline IV & $42 \pm 7$ & \pm 16 & $\pm 16^{b)}$ \\
\hline V & $53 \pm 9^{b)}$ & $\pm 12^{b)}$ & $\pm 13^{b)}$ \\
\hline VI & $60 \pm 10^{b)}$ & $\pm 12^{a, b)}$ & $\pm 15^{b)}$ \\
\hline
\end{tabular}

$10 \mu \mathrm{g} / \mathrm{g}$ ). The $\mathrm{Zn}$ concentration increased in a dosedependent manner. Correlation coefficients between $\mathrm{Cd}$ and $\mathrm{Zn}$ are shown in Table 3. Although a correlation between $\mathrm{Cd}-\mathrm{Cu}$ was not seen $(p>0.05$, data not shown), a significant correlation coefficient was observed between $\mathrm{Cd}$ and $\mathrm{Zn}$ after 18 months, except for groups II and VI at 18 months, and groups II and III at 22 months.

\section{Concentration of $\mathrm{Cd}, \mathrm{Cu}$, and $\mathrm{Zn}$ in the Kidneys}

The changes in $\mathrm{Cd}$ concentration in the kidneys resembled those in the liver (Table 4). That is, the concentrations increased in a dose-dependent manner for the first 18 months and remained the same thereafter. The concentrations of $\mathrm{Cu}$ increased in a dose-dependent manner at 12 and 18 months, and at 22 months the concentrations also increased but not in a statistically significant manner. Although the $\mathrm{Zn}$ concentration increased more in the 5-ppm group, the increase was not dose dependent. No correlation between $\mathrm{Cd}$ and $\mathrm{Cu}$ or $\mathrm{Zn}$ in the kidney was observed ( $p>0.05$, data not shown).
Table 3. Pearson's Correlation Coefficients between $\mathrm{Cd}$ and $\mathrm{Zn}$ Concentrations in the Liver of Rats Fed CdPolluted rice or Cd-Supplemented Diet for 12, 18, and 22 months

\begin{tabular}{|c|c|c|c|}
\hline & 12 months & 18 months & 22 months \\
\hline I & $-0.0189(10)^{a)}$ & $0.798 \quad(7)^{*}$ & $0.767(11)^{* *}$ \\
\hline II & $0.126 \quad(10)$ & $0.743 \quad(6)$ & $0.609 \quad(9)$ \\
\hline III & $0.439 \quad(10)$ & $0.912(7)^{* *}$ & $0.202 \quad(9)$ \\
\hline IV & $0.445 \quad(10)$ & $0.959(7)^{* *}$ & $0.949(8)^{* *}$ \\
\hline $\mathrm{V}$ & $0.0814(10)$ & $0.964(5)^{* *}$ & $0.918(6)^{* *}$ \\
\hline VI & $-0.473 \quad(10)$ & $0.0621(7)$ & $0.812(9)^{* *}$ \\
\hline
\end{tabular}

\section{DISCUSSION}

Some studies showed that $\mathrm{Cd}$ administered to laboratory animals induced elevated $\mathrm{Zn}$ and $\mathrm{Cu}$ concentrations in the liver and kidneys. In this study, a significant increase in $\mathrm{Zn}$ concentration in the liver and kidneys was observed in all Cd-treated groups. These results were in agreement with our previous results of a 2-and 4-months exposure experiment. ${ }^{18)}$ 
Table 4. Concentrations of $\mathrm{Cd}, \mathrm{Cu}$, and $\mathrm{Zn}$ in the Kidneys of Rats Fed Cd-Polluted Rice or CdSupplemented Diet for 12, 18, and 22 months

\begin{tabular}{|c|c|c|c|c|}
\hline Group & \multicolumn{2}{|c|}{12 months } & 18 months & 22 months \\
\hline \multicolumn{5}{|l|}{$\mathrm{Cd}$} \\
\hline I & 0.03 & \pm 0.012 & $0.20 \pm 0.07^{a)}$ & $\left.0.12 \pm 0.05^{a}\right)$ \\
\hline II & 1.4 & \pm 0.3 & $4.5 \pm 2.3^{a)}$ & $7.0 \pm 4.3^{a)}$ \\
\hline III & 2.8 & $\pm 1.5^{b)}$ & $4.8 \pm 2.8$ & $5.6 \pm 4.2^{a)}$ \\
\hline IV & 7.9 & $\pm 2.4^{b)}$ & $20 \pm 7^{a, b)}$ & $31 \pm 16^{a, b)}$ \\
\hline V & 29 & $\pm 4^{b)}$ & $67 \pm 24^{a, b)}$ & $\pm 16^{a, b)}$ \\
\hline VI & 45 & $\pm 7^{b)}$ & $120 \pm 20^{a, b)}$ & $\pm 25^{a, b)}$ \\
\hline \multicolumn{5}{|l|}{$\mathrm{Cu}$} \\
\hline I & 18 & \pm 7 & $6.6 \pm 2.0^{a)}$ & \pm 4 \\
\hline II & 16 & \pm 5 & $9.7 \pm 3.0^{a)}$ & $16 \pm 5$ \\
\hline III & 15 & \pm 3 & $8.0 \pm 1.9^{a)}$ & \pm 9 \\
\hline IV & 20 & \pm 5 & $9.2 \pm 1.4^{a)}$ & \pm 7 \\
\hline V & 24 & \pm 5 & $14 \pm 4^{a, b)}$ & \pm 12 \\
\hline VI & 29 & $\pm 9^{b)}$ & $14 \pm 6^{a, b)}$ & \pm 14 \\
\hline \multicolumn{5}{|l|}{$\mathrm{Zn}$} \\
\hline I & 35 & \pm 2 & $29 \pm 2^{a)}$ & \pm 3 \\
\hline II & 35 & \pm 4 & $33 \pm 2$ & $35 \pm 4$ \\
\hline III & 34 & \pm 3 & \pm 5 & \pm 5 \\
\hline IV & 38 & \pm 2 & $\pm 4^{b)}$ & $\pm 6^{a, b)}$ \\
\hline V & 43 & $\pm 4^{b)}$ & $40 \pm 2^{b)}$ & \pm 7 \\
\hline VI & 44 & $\pm 3^{b)}$ & $\pm 6^{b)}$ & $\pm 7^{b)}$ \\
\hline
\end{tabular}

Values of Cd concentration are cited from our previous data. ${ }^{15)}$ a) Significantly different from 12 months, $p<0.05$. b) Significantly different between treatment group and control group (group I), $p<0.05$.

Cd toxicity affects the intestinal absorption of $\mathrm{Zn}$ and $\mathrm{Cu}$ because of $\mathrm{Cd}$-induced enteropathy. ${ }^{19)} \mathrm{We}$ assumed that the enteropathy was not induced based on urinalysis and blood chemistry data and pathologic assessments of the liver and kidneys. Therefore this increase is likely due to the de novo synthesis of metallothionein induced by $\mathrm{Cd}$ administration. ${ }^{20,21)}$ The metallothionein concentration in the kidneys in the 5-, 20-, and 40-ppm groups increased at every time point in a dose-dependent manner. ${ }^{15)}$ In the liver, metallothionein increased in the 20- and 40-ppm groups from 12 months, but the liver $\mathrm{Cu}$ concentration did not increase. Pearson correlation coefficient analysis also revealed a clear relationship between $\mathrm{Cd}$ and $\mathrm{Zn}$, but not between $\mathrm{Cd}$ and $\mathrm{Cu}$. Therefore the increase in $\mathrm{Zn}$ concentration may not always be based on induction of metallothionein, and we cannot rule out the possibility that the high correlation coefficient between $\mathrm{Cd}$ and $\mathrm{Zn}$ in the control group had another cause.

Both $\mathrm{Cu}$ and $\mathrm{Zn}$ are known to be important prosthetic groups for many metalloenzymes, including superoxide dismutase, DNA polymerase, and carbonic anhydrase. Thus any alteration in the homeo- stasis of these metals can also be detrimental to the activity of these enzymes and may influence human health.

\section{REFERENCES}

1) WHO (1992a) Environmental Health Criteria 134 Cadmium, World Heath Organisation, Geneva.

2) WHO (1992b) Environmental Health Criteria 135 Cadmium-Environmental Aspect, World Heath Organisation, Geneva.

3) Friberg, L., Piscator, M., Nordberg, G. and Kjellstr, M. T. (1974) Cadmium in the Environment, 2nd ed., CRC Press, Cleveland, Ohio.

4) Gunderson, E. L. (1988) FDA total diet study, April 1982-April 1984, dietary intakes of pesticides selected elements, and other chemicals. J. Assoc. Off. Anal. Chem., 71, 1200-1209.

5) Gunderson, E. L. (1995) Dietary intakes of pesticide, selected elements, and other chemicals: FDA total diet study, June 1984-April 1986. J. AOAC Int.,78, 910-921.

6) Gunderson, E. L. (1995) FDA total diet study, July 1986-April 1991, dietary intakes of pesticides 
selected elements, and other chemicals. J. AOAC Int., 78, 1353-1363.

7) MacIntosh, D. L., Spengler, J. D., Oekaynak, H., Tsai, L. and Ryan, P. B. (1996) Dietary exposures to selected metals and pesticides. Environ. Health Perspect., 104, 202-209.

8) Tsuda, T., Inoue, T., Kojima, M. and Aoki, A. (1995) Market basket and duplicate portion estimation of dietary intakes of cadmium, mercury, arsenic, copper, manganese, and zinc by Japanese adults. $J$. AOAC Int., 78, 1363-1368.

9) Rivai, I. F., Koyama, H. and Suzuki, S. (1990) Cadmium content in rice and its daily intake in various countries. Bull. Environ. Contam. Toxicol., 44, 910-916.

10) Herawati, N., Suzuki, S., Hayashi, K., Rivai, I. F. and Koyama, H. (2000) Cadmium, copper, and zinc levels in rice and soil of Japan, Indonesia, and China by soil type. Bull. Environ. Contam. Toxicol., 64, 33-39.

11) Mills, C. F. and Dalgarno, A. C. (1972) Copper and zinc status of ewes and lambs receiving increased dietary concentrations of cadmium. Nature (London), 239, 171-173.

12) Bremner, I. (1974) Heavy metal toxicities. Q. Rev. Biophys., 7, 75-124.

13) Stonard, M. D. and Webb, M. (1976) Influence of dietary cadmium on the distribution of the essential metals copper, zinc and iron in tissues of the rats. Chem--Biol. Interact., 15, 349-363.

14) Abdulla, M. and Chmielnicka, J. (1990) New aspects on the distribution and metabolism of essential trace elements after dietary exposure to toxic metals. Biol. Trace Elem. Res., 23, 25-53.

15) Shibutani, M., Mitsumori, K., Satoh, S., Hiratsuka,
H., Satoh, M., Sumiyoshi, M., Nishijima, M., Katsuki, Y., Suzuki, J., Nakagawa, J., Akagi, T., Imazawa, T. and Ando, M. (2001) Relationship between toxicity and cadmium accumulation in rats given low amounts of cadmium chloride or cadmium-polluted rice for 22 months. J. Toxicol. Sci., 26, 337-358.

16) Hiratsuka, H., Satoh, S., Satoh, M., Nishijima, M., Katsuki, Y., Suzuki, J., Nakagawa, J., Sumiyoshi, M., Shibutani, M., Mitsumori, K., Tanaka-Kagawa, T. and Ando, M. (1999) Tissue distribution of cadmium in rats given minimum amounts of cadmium-polluted rice or cadmium chloride for 8 months. Toxicol. Appl. Pharmacol., 160, 183-190.

17) God, S. C. and Weil, C. S. (1994) Statistics for toxicologists. In Principles and Methods of Toxicology, $3^{\text {rd }}$ edition (Hayes, A. W., Ed.), Raven Press, New York, pp. 221-274.

18) Oishi, S., Nakagawa, J. and Ando, M. (2001) Effects of ingestion of cadmium-polluted rice or low-dose cadmium-supplemented diet on the endogenious metal balance in female rats. Biol. Trace Elem. Res., 84, 155-167.

19) Murata, I., Hirono, T., Saeki, Y. and Nakagawa, S. (1970) Cadmium enteropathy, renal osteomalacia (Itai-Itai desease in Japan). Bull. Soc. Int. Chir., 2, 34-42.

20) Sugawara, N. (1977) Influence of cadmium on zinc distribution in the mouse liver and kidney: role of metallothionein. Toxicol. Appl. Pharmacol., 42, 377386.

21) Stonard, M. D. and Webb, M. (1976) Influence of dietary cadmium on the distribution of the essential metals copper, zinc, and iron in tissues of the rat. Chem.-Biol. Ineract., 15, 349-363. 